\title{
Adhesive Strength of Primers for Automotive Repair Painting under Various Roughness Conditions
}

\author{
${ }^{1} \mathrm{Ju}-\mathrm{Ho}$ Lee, ${ }^{2}$ Sung-Wan Hwang, ${ }^{3}$ Ho-Kyung Kim \\ ${ }^{1}$ Graduate School of ND Fusion, \\ ${ }^{2}$ Department of Automotive Engineering, Graduate School, \\ ${ }^{3}$ Department of Mechanical and Automotive Engineering, \\ Seoul National University of Science and Technology, 139-743, Seoul, Republic of Korea
}

\begin{abstract}
The aim of this study is to evaluate the adhesive strength of an oil-soluble primer under various sanding conditions for automotive panel repair painting. The adhesive strengths of paint coatings with various surfacers on steel surfaces were evaluated with variation of their surface roughness levels using various grades of sand paper. After the sanding process to instill different degrees of roughness, the surface in each trial was painted onto a steel plate coupon using a lacquer surfacer, a primer mixed surfacer, a surfacer with a wash primer and a surfacer with an epoxy primer. For each sample, the adhesive strength of paint coating was evaluated with a miniaturized tensile testing machine after the complete age-hardening of the painting over a corresponding elapsed time of 150 days. It was found that a coupon with a rougher surface generally, exhibited higher adhesive strength. The adhesive strength of paint coating under the as-received steel coupon (without a sanding process) was much lower than that of the paint coatings which were sanded. The adhesive strengths of the surfacer with a wash primer and the lacquer surface were 0.64 and $0.49 \mathrm{MPa}$, respectively. The adhesive strength of the surfacer with a primer was found to be higher than that without a primer.
\end{abstract}

Key words: Adhesive strength, repair painting, oil-soluble primers, roughness, automotive, variation

\section{INTRODUCTION}

When repairing a car accident panel, the panel is painted after sheeting or is replaced with a new one. When undertaking the sheeting and painting steps research is required to peel off the old film of the area to be repaired and to create a suitable base surface. Removing the old paint coating is done using a sanding machine and abrasive paper. The surface of the steel plate often protrudes during the polishing process, if the coating film is severely damaged. A wash primer, epoxy primer, primer surfacer or other similar substance is either applied or not according to the person doing the work. These repair methods affect the adhesive strength, corrosion resistance and chemical resistance of the steel plate surface and the repaired surface of the automobile body. As a result, the repair method is an important factor affecting the quality of the paint coating. Particularly, the adhesive strength is a major factor affecting the mechanical properties of the paint coating.

Thus far, many studies have assessed the performance capabilities of paint coatings. For example, Nichols et al. (1999) studied the weathering effect on the mechanical properties of automotive paint coatings. They proposed a method by which to predict the fracture energy and the mechanical performance of the coating layer due to long-term weathering by measuring the thermal stress caused by the effects of the humidity of the coating layer. Devos et al. (2001) applied a three-point bending test to evaluate the adhesive performance of paint coatings while also evaluating the acoustic emission characteristics during the test. The rupture energy of the paint coating layer was measured through a three-point bending test and the bending test was reported to be an effective test method to provide information about the damage mechanism for evaluating the adhesion of paint coatings. Song et al. (2011) investigated the mixing ratio of polyethylene and polyurethane to improve the adhesion of paint coatings. It was reported that when paint containing $25 \%$ or more of thermoplastic polyurethane is applied as the top paint layer, the adhesion is remarkably improved. Tahmassebi and Moradian (2004) evaluated the wear resistance, scratch resistance and adhesive strength between clear coatings and base coatings in order to predict the weathering performance of automotive coatings composed of base

Corresponding Author: Ju-Ho Lee, Graduate School of NID Fusion, Seoul National University of Science and Technology 139-743, Seoul, Republic of Korea 
coating and clear coating components. They reported that a capping test and a hardness test were not sufficient for evaluating the performance capabilities of these coatings during long-term weathering to evaluate apparent changes. However, few studies have evaluated the adhesive strengths of various primer coatings applied to automotive repair applications.

Repair painting depends on the severity of the damage to the vehicle body. In cases of major body damage, repair painting is nearly a type of replacement work. Normally, in cases of average or minor body damage, the worker peels off the damaged coating and pulls out the recessed part after a stud welding step. The surface of this part is sanded, primer is applied, putty is applied and the base and top coatings are applied onto the surface. At this time, the overall adhesive strength of the paint coating is determined, depending on the sanding condition of the damaged surface and the type of primer applied. Therefore, in this study, we evaluate the effect of different types of sanding treatments and applied primers on the adhesive strength capabilities of repair paint coatings. Also in this study, the adhesive strength is evaluated by applying a lacquer surfacer a primer-mixed surfacer, a surfacer with a wash primer and a surfacer with an epoxy primer while varying the surface roughness of a cold-rolled steel sheet by applying various grades of abrasive paper. Based on the results, a suitable coating method is derived for repair painting considering the adhesive strength.

\section{MATERIALS AND METHODS}

Specimen preparation and test method: For the evaluation of the adhesive strengths of the repair paint coatings a $40 \times 70 \mathrm{~mm}$ cold-rolled steel plate coupon with a thickness of $0.8 \mathrm{~mm}$ of the type used in manufacturing of automotive body panels was used in each case. In order to evaluate the effect of the surface roughness on the adhesive strength of the steel sheets, various grades of abrasive paper $(120,180,220$ and $\# 320)$ were used so, that, different surface roughness levels could be evaluated. The surface roughness levels of the steel sheets were $\mathrm{Ra} 1.32,0.76$, 0.48 and 0.30 , respectively, after polishing with 120,180 , 220 and \#320 abrasive papers, respectively. The surface roughness of the sheet in the as-received condition is Ra 2.00. Four different painting methods typically used to repair painting operations were applied here to paint the specimens processed with various degrees of surface roughness.

Surface contaminants were removed using a degreaser for the preparation of the test specimens. All of the specimens were polished using a sanding machine with abrasive papers of $120,180,220$ and \#320 under a weight of $5 \mathrm{kgf}$ in order to ensure constant roughness levels for the specimens. After a second degreasing step, the different paint mixes were applied in a spray booth at a temperature of $20^{\circ} \mathrm{C}$. The pressure of the nozzle of the spray gun was fixed at approximately 2.5 bar during the painting process. After being coated, each sample was dried in a specimen dryer at $60^{\circ} \mathrm{C}$ for $20 \mathrm{~min}$. Information on each painting mix is given below.

Lacquer surfacer: A natural dry-type of paint (PS220LV) with main components of toluene, talc, titanium dioxide and methyl isobutyl ketone was used. A thinner was added at a ratio of 50:50 and the coating thickness ranged from $40-50 \mu \mathrm{m}$.

Surfacer with an epoxy primer: A butyl acetate-based epoxy primer (410-48248) was initially sprayed on the specimen at a thickness of 10-15 $\mu \mathrm{m}$ after which a second coating was applied using a primer surfacer (PS-330).

Surfacer with a wash primer: A wash primer (D-831) of which the main components are isobutyl alcohol, n-butyl acetate and xylene is diluted at a ratio of 50:50 with a thinner and initially sprayed to a thickness of 10-15 $\mu \mathrm{m}$. After give $5 \mathrm{~min}$ a surfacer (PS-330) was painted on as a second coating.

Primer mixed surfacer: $\times y$ lene, talc and a barium sulphate-based primer (PS-330) a hardener (PSH-513) and a diluent (TH-0045) were mixed at acorresponding ratio of $5: 1: 2$. The coating thickness of the painted steel plate in each case was measured using a film thickness meter (Elcometer A456FBS). Various methods have been applied to evaluate the adhesive strength of a film coated onto a specimen (5) (Anonymous, 2009) is the most widely used method for a quantitative evaluation of adhesive strength levels. Anonymous (2009) is a general pull-off method which can be used to measure the mechanical adhesive strength of a coating film. It involves attaching a flat disk to the coating film and then applying a tensile load to the coating film.

It is very important to measure the adhesive strength while keeping the adhesive surface and load direction of the coated specimen perpendicular. In order to guarantee the force normal to the specimen surface, a special test jig was designed as shown in Fig. 1. In this system, a paint coating is bonded to a disc with an adhesive and a tensile load is applied to a fixture connected with a bolt. In this case, the ball knob used is composed of a jig with a Teflon ring, so that, the ball knob can be freely rotated in order for the vertical load to be accurately applied to the 
coating. Using the jig designed in this way a tensile test was carried out using a small tensile tester that applied a tensile load to the fixture as shown in Fig. 2. The tensile load rate was applied within the speed range specified in ASTM D4541 (5). During this process, the surface of the test jig disk was cleaned thoroughly after grinding it with $\# 800$ abrasive paper. The disk was made to adhere to the flat surface of the test specimen with an adhesive under a constant vertical load and the tensile test was performed after the adhesive was sufficiently cured.

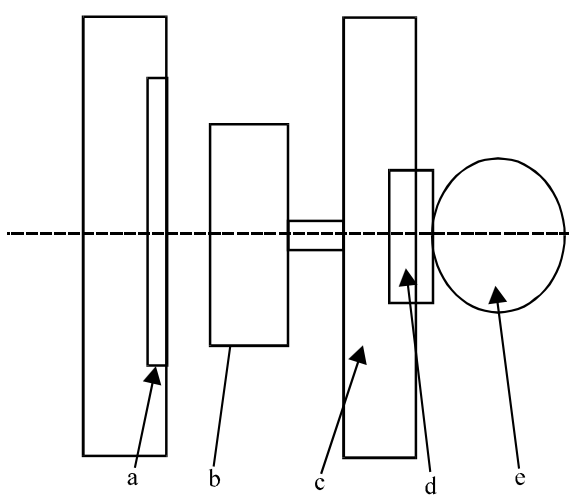

Fig. 1: Schematic of the tensile test for the measurement of the adhesive force of the paint: a) Specimen; b) Disk; c) Fixture; d) Teflon spacer and e) Ball knob

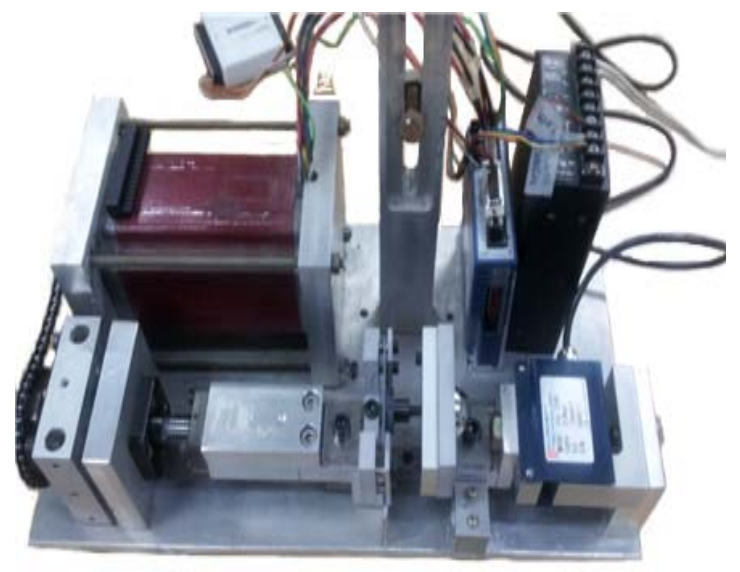

Fig. 2: Miniaturized tensile testing machine used, here, to measure the adhesive strength of the paint

\section{RESULTS AND DISCUSSION}

Film thicknesses of the test specimens: The cross-sectional shapes of the cold-rolled steel plate specimens coated with various paint formulations are shown in Fig. 3. Table 1 shows the results of measurements of the film thickness on the steel coupons with various roughness levels coated with various coating types. The thickness deviation of each test specimen coating was $\pm 5.0 \mu \mathrm{m}$ due to differences in the spray pattern widths during the paint coating process. The average thickness of the lacquer surfacer is $65.9 \mu \mathrm{m}$ while the average thickness of the primer-mixed surfacer shows the minimum value among all the coating thicknesses at $44.9 \mu \mathrm{m}$.

Generally, the primer protects the plate from corrosion and/or physical impacts and increases the adhesion of the paint coating. However, it is considered that the thickness of the specimen painted with the lacquer surfacer is thicker than that of the other surfacers because the lacquer surfacer alone provides a thicker coat as protection from corrosion and/or physical impacts, identical to the function of the primer. However, for the primer-mixed surfacer, the coating layer was thinnest due to the characteristics of how the primer-mixed surfacer was applied which differed from how a primer and then a surfacer coating are applied.

Evaluation of the coating adhesive strength: The adhesive strength was evaluated based on a bonding surface area of $53.3 \mathrm{~mm}^{2}$ for six test specimens under each condition. The adhesive strength was determined based on the experimental data after curing for 150 days during which it was determined that the coating layer of each test specimen was sufficiently cured. Figure 4 shows photographs of the experimental results of a test specimen 30 and 150 days after it was painted. These results suggest that the primer applied in order to improve the adhesion of the surfacer is completely cured on the plate after 150 days.

Figure 5 shows the adhesive strength before and after curing for the specimens onto which the surfacer with an epoxy primer was applied. For the as-received test specimens and \#120 abrasive polished test specimens,

Table 1: Thickness measurement results of the paint coatings on the specimens [unit: $\mu \mathrm{m}$ ]

\begin{tabular}{|c|c|c|c|c|}
\hline Roughness condition & $\begin{array}{l}\text { Lacquer surface } \\
\text { (= lacquer } 1 \mathrm{~K})\end{array}$ & $\begin{array}{l}\text { Primer-mixed surface } \\
\quad(=\text { primer } 2 \mathrm{~K})\end{array}$ & $\begin{array}{l}\text { Surfacer with a wash } \\
\text { primer (= wash } 2 K \text { ) }\end{array}$ & $\begin{array}{l}\text { Surfacer with an epoxy } \\
\text { primer (= epoxy } 2 K)\end{array}$ \\
\hline As-received & 70.1 & 48.5 & 60.4 & 46.9 \\
\hline$\# 120$ & 63.5 & 46.7 & 61.0 & 63.6 \\
\hline$\# 180$ & 62.1 & 40.8 & 56.4 & 61.0 \\
\hline$\# 220$ & 65.2 & 42.9 & 56.3 & 63.7 \\
\hline$\# 320$ & 68.7 & 45.7 & 61.9 & 64.8 \\
\hline
\end{tabular}




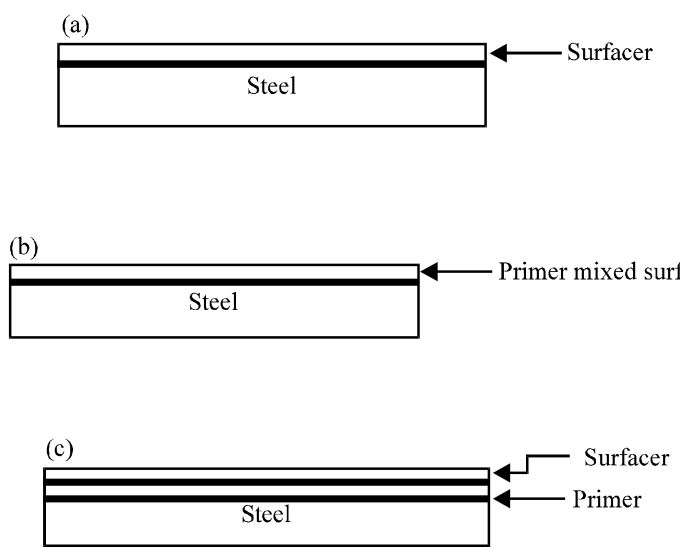

Fig. 3: Configuration of the three types of specimens: a) Lacquer surface (= lacquer $1 \mathrm{~K}$ ); b) Primer-mixed surface (= primer $2 \mathrm{~K})$; (c) Surfacer with an epoxy primer (= epoxy $2 \mathrm{~K})$ and surfacer with a wash primer (= wash $2 \mathrm{~K})$ (a)

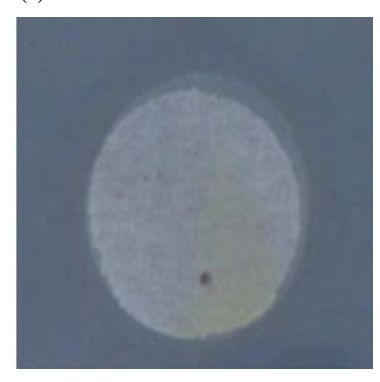

(b)

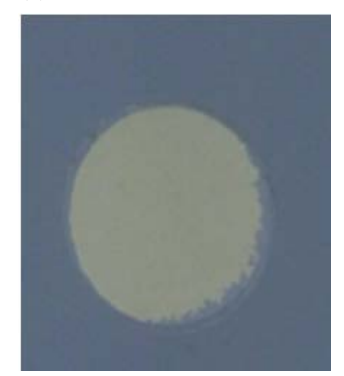

Fig. 4: Comparison of a specimen to assess the curing: a) After 30 and b) After 150 days

the adhesive strength decreased after curing compared to that before curing. However, the adhesive strengths of the specimens polished with the 180,220 and $\# 320$ abrasive papers increased after curing. Specifically, the specimens polished with the \#320 paper increased by more than $90 \%$ after curing compared to those before curing. Thus, additional examinations of the adhesive strength according to the curing period and the different paint coating conditions are needed.

Figure 6 shows the results of adhesion strength tests of specimens polished with various grades of abrasive paper. Figure 6 shows that the strength of the lacquer surfacer directly painted onto the as-received steel sheet is the lowest among the four types of paint coatings. Unlike the other test specimens, the lacquer surfacer was directly applied to the plate without a primer, hence, the adhesion depends on only the adhesion of the lacquer surfacer on the sheet. Therefore, the strength is lower

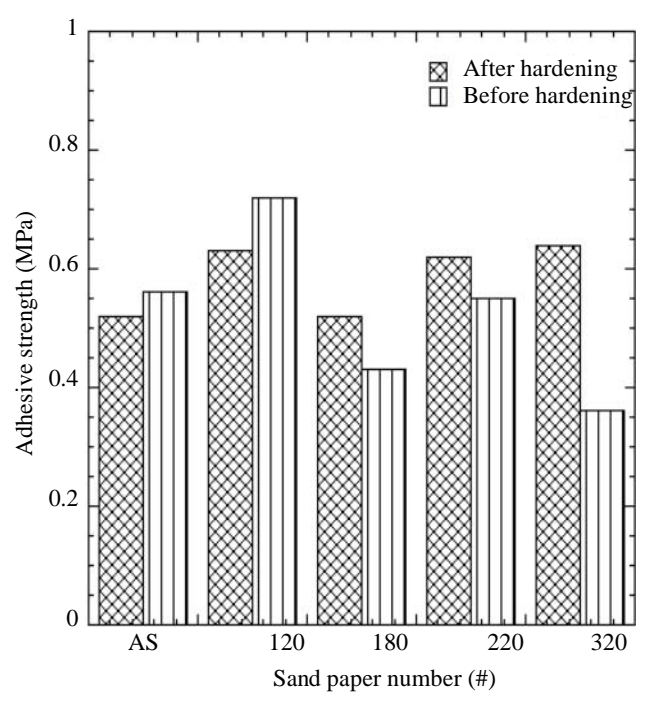

Fig. 5: Effect of curing on adhesive strength for the specimens coated with the surfacer with an epoxy primer

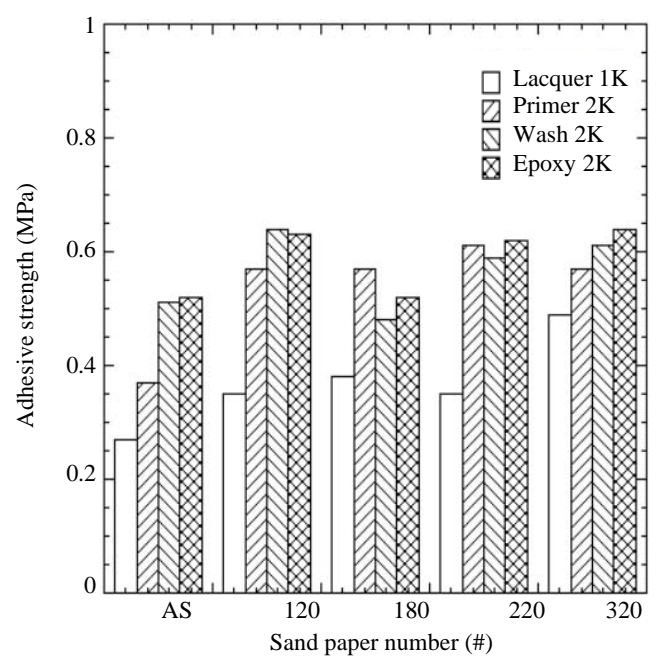

Fig. 6: Comparison of the experimental adhesive strengths against the surface roughness for the four specimens with different coating conditions

than those of the test specimens also coated with primer-containing coating. In addition, the specimen scoated with the surfacer with a wash primer on the sheet polished with \#120 abrasive paper shows the highest adhesive strength of $0.64 \mathrm{MPa}$.

On the other hand, the specimens painted using a surfacer with a wash primer and an epoxy primer showed the highest adhesive strength and a similar adhesive strength. These results suggest that the primer enhances the adhesive strength of the surfacer. Based on the 
conclusion that high levels of adhesive strength resulted when the specimens were polished by abrasive papers, it can be predicted that making the surface of the plate material constant using abrasive paper and then spraying a surfacer onto the surface will lead to high adhesive strength. Because the primer-mixed surfacer test specimens used a mix of a surfacer and a primer, they have the advantage of a lighter weight given the lamination of the thin coating of film. However, it is considered that additional studies are needed to compare the adhesive strength levels of these paint coatings with similar coating thicknesses because the primer-mixed surfacer with a thinner thickness showed lower adhesive strength than the paint coatings with the wash primer and epoxy primer in this study. Among the specimens polished with abrasive paper the adhesion strengths when using the 120,220 and $\# 320$ abrasive papers but not $\# 180$ were similar and the adhesive strength of the specimens polished with \#120 abrasive paper was highest at $0.64 \mathrm{MPa}$. Therefore, it is considered that the most effective method to ensure high adhesive strength is to apply a surface treatment using \#120 abrasive paper in order to shorten the time of the coating operation when the surface of the steel plate is severely exposed to air due to for instance an accident.

The adhesion strength levels of two coatings coated onto test specimens polished to a certain degree of roughness using an abrasive surface and specimens having the surface condition of a typical cold-rolled steel sheet without abrasive paper polishing were found to vary greatly. Four types of test specimens polished using abrasive papers were found to have a coating layer on the base plate which is believed to improve the adhesion between the plate and the paint when the paint is sprayed between the rough surface features. Moreover, for the specimens with the cold-rolled steel sheet surfaces which were not sanded with abrasive paper, it was considered that the surface in each case was uneven when the paint was applied which prevented the paint from completely adhering onto the sheet surface.

\section{CONCLUSION}

In this study, we evaluated the adhesive strengths of paint coatings which contained a lacquer surfacer a primer surfacer a wash primer and an epoxy primer applied onto cold-rolled steel plates in order to determine the most suitable coating method in terms of the adhesive strength for the repair painting of automotive steel plate materials. For this purpose, the thicknesses of four types of paint coatings were measured and the adhesive performance capabilities were evaluated through adhesive strength tests. The results are summarized as follows. The mean coating thickness of lacquer surfacer was highest at $65.9 \mu \mathrm{m}$ while the average coating thickness of the primer-mixed surfacer was thinnest at $44.9 \mu \mathrm{m}$. The coated specimens polished with \#120 abrasive paper and coated with a coating containing a wash primer showed the highest adhesive strength. The adhesive strength of the specimens coated with a surfacer with a wash primer, at $0.64 \mathrm{MPa}$ was increased by approximately $31 \%$ compared to that of the specimen coated with a lacquer surfacer. The adhesion strength of the paint coating on the as-received test specimens was generally poor and was lower than that when the lacquer surfacer was used. In terms of the adhesive strength, the best sanding process for a repair coating was found after polishing with \#120 abrasive paper.

\section{ACKNOWLEDGEMENT}

This study was financially supported by Seoul National University of Science and Technology.

\section{REFERENCES}

Anonymous, 2009. ASTM D4541-09: Standard test method for pull-off strength of coatings using portable adhesion testers. ASTM International, West Conshohocken, PA., USA. https://www.astm.org/ DATABASE.CART/HISTORICAL/D4541-09.htm.

Devos, P., Y. Baziard, B. Rives and P. Michelin, 2001. Adherence evaluation of paint coatings using a three-point flexure test and acoustic emission. J. Appl. Polym. Sci., 81: 1848-1857.

Nichols, M.E., J.L. Gerlock, C.A. Smith and C.A. Darr, 1999. The effects of weathering on the mechanical performance of automotive paint systems. Prog. Org. Coat., 35: 153-159.

Song, J., A. Batra, J.M. Rego and C.W. Macosko, 2011. Polyethylene/polyurethane blends for improved paint adhesion. Prog. Org. Coat., 72: 492-497.

Tahmassebi, N. and S. Moradian, 2004. Predicting the performances of basecoat/clearcoat automotive paint systems by the use of adhesion, scratch and mar resistance measurements. Polym. Degrade. Stab., 83: 405-410. 